Manten, A. \& Rowley, D. (1953). J. gen. Microbiol. 9, 226-233.

\title{
Genetic Analysis of Valine Inhibition in the K12 Strain of Bacterium coli
}

\author{
By A. MANTEN \\ National Institute of Public Health, Utrecht, Holland \\ AND D. ROWLEY \\ The Wright-Fleming Institute of Microbiology, St Mary's Hospital \\ Medical School, Paddington, London, W. 2
}

SUMMARY: Development of resistance to valine by the $\mathrm{K} 12$ strain of Bacterium coli (Escherichia coli) has been found to occur by a one-step process leading to full resistance in every case. The genetic factors controlling this valine resistance have been studied by recombinant analyses. The results indicate a very close linkage between valine resistance and leucine independence. These substances have previously been shown to bear special relationship to each other with respect to the $\mathrm{K} 12$ strain.

It has been observed recently that various bacteria which are capable of growth on media containing ammonia as the sole source of nitrogen are unable to grow when minute amounts of certain specific amino-acids are added to the medium. One of the most remarkable examples is that of the well known $\mathrm{K12}$ strain of Bacterium coli (Escherichia coli) used by Lederberg \& Tatum (1946) for their genetic studies. This strain is completely inhibited by less than $1 \mu \mathrm{g}$. DL-valine/ml. of the medium (Tatum, 1949; Rowley, 1953). All other aminoacids (except norleucine) appear to be inactive against this strain. The inhibition due to DL-valine can be prevented by the simultaneous presence of even smaller concentrations of leucine or isoleucine. So far as is known little genetic study has been made with these inhibitions and it seems desirable to ascertain to what extent this phenomenon is genetically controlled.

Various nutritionally exacting mutant strains derived from K 12 (see Table 1) were, with one exception, found to be equally susceptible to inhibition by valine as was the parent strain. Valine-resistant strains were developed from these mutants by seeding heavily onto valine-containing plates. A series of crosses between valine-resistant and valine-sensitive mutants were then made and the nutritionally non-exacting (prototrophic) colonies developing from these recombinations were examined for their response to valine. Further crossings were seeded onto minimal medium containing thiamine or threonine to investigate possible linkage between these factors and valine resistance.

\section{MATERIALS AND METHODS}

The minimal medium used was that of Davis \& Mingioli (1950). The mutant strains derived from $\mathrm{K} 12$ had requirements as shown in Table 1. The aminoacids used were all DL racemates as supplied by British Drug Houses Ltd. Sensitivity to valine was determined by streaking a bacterial suspersion in sterile water up to ditches containing $100 \mu \mathrm{g}$. valine $/ \mathrm{ml}$. cut in minimal medium plates to which supplements had been added when required. 
Table 1. Sensitivity to valine and nutritional requirements of mutants derived from $\mathrm{K} 12$

\begin{tabular}{|c|c|c|}
\hline Strain & Requirement & $\begin{array}{l}\text { Sensitivity } \\
\text { to valine }\end{array}$ \\
\hline $\mathbf{K} 12$ & None & $\mathbf{S}$ \\
\hline W677 & Threonine, leucine, thiamine $\left(\mathrm{TLB}_{1}-\right)$ & $\mathbf{R}$ \\
\hline $58-161$ & Biotin, methionine (B.M. - ) & $\mathbf{S}$ \\
\hline J4-5 & Tryptophan, histidine & $\mathbf{S}$ \\
\hline J 6-2 & Tryptophan, histidine, proline & $\mathbf{S}$ \\
\hline J5-3 & Proline, methionine (P.M. - ) & $\mathbf{S}$ \\
\hline J5-10 & Proline, histidine (P.H. -) & $\mathbf{S}$ \\
\hline
\end{tabular}

All supplements added at $20 \mu \mathrm{g} . / \mathrm{ml}$. except biotin which was $1 \mu \mathrm{g} . / \mathrm{ml}$.

\section{RESULTS}

\section{Acquired resistance to valine}

Of the mutant strains used only $W 677$ appeared to be naturally resistant. The wild type (K12) and the derived mutants 58-161, J 4-5 and J 5-10 were used in further experiments as they gave sharply defined zones of inhibition with valine.

To determine the rate at which resistant cells develop, minimal medium plates containing $1,2,4,10,100$ and $1000 \mu \mathrm{g}$. DL-valine $/ \mathrm{ml}$. were seeded with $3 \times 10^{8}$ cells of $\mathrm{K} 12$ and incubated at $37^{\circ}$ for 2 days. It can be seen from Table 2 that approximately the same number of resistant cells arose with each concentration of valine.

Table 2. Number of valine-resistant cells developing at varying valine

Concentration of
DL-valine
$(\mu \mathrm{g} \cdot / \mathrm{ml}$.
1
2
4
10
100
1000

$$
\begin{gathered}
\begin{array}{c}
\text { No. of cells } \\
\text { inoculated }
\end{array} \\
3 \times 10^{8} \\
3 \times 10^{8} \\
3 \times 10^{8} \\
3 \times 10^{8} \\
3 \times 10^{8} \\
3 \times 10^{8}
\end{gathered}
$$

$\begin{gathered}\text { No. of colonies } \\ \text { developing }\end{gathered}$
184
196
143
167
134
115

Ratio; res./sens.

$$
\begin{aligned}
& 6 \cdot 1: 10^{7} \\
& 6 \cdot 5: 10^{7}
\end{aligned}
$$$$
4 \cdot 8: 10^{7}
$$$$
5 \cdot 6: 10^{7}
$$$$
4 \cdot 4: 10^{7}
$$

$3 \cdot 8: 10^{7}$

When the resistant colonies which developed at each valine concentration were subsequently examined for sensitivity to valine, it was found that they were all resistant to $1000 \mu \mathrm{g}$. valine/ml. This rather surprising result is quite different from those which occur with penicillin or even streptomycin and it seems that resistance to valine develops as a one-step mutation, giving rise only to mutants of the completely resistant variety. As the development of resistance to penicillin has been described as 'obligatory multistep' and that to streptomycin 'faculative multistep' (Hsie \& Bryson, 1950; Bryson \& Szybalski, 1952) development of resistance to valine may be designated as belonging to an 'obligatory one-step pattern'. Valine resistance, once acquired, was maintained through many subcultures on media with and without valine. With the four 
valine-resistant strains used in these experiments no reversion to sensitivity could be detected after fifteen transfers on minimal medium or nutrient agar slopes.

\section{Genetics of valine resistance}

In an attempt to elucidate the genetics of valine resistance, crossing experiments were performed with the four $\mathrm{K} 12$ mutants 58-161, J 4-5, J 5-10 and W677. Of these mutants only the last is naturally resistant to valine, but resistant mutants of the first three strains were selected and are designated with the superscript ' $\mathrm{B}$ '.

Strains were grown overnight at $37^{\circ}$ in liquid minimal medium supplemented with the appropriate amino-acids and vitamins as required (Table 1). Valineresistant strains were cultivated in the presence of $1000 \mu \mathrm{g}$. DL-valine/ml. to ensure the growth of resistant cells only.

The incidence of genetic recombination was detected by applying Tatum \& Lederberg's (1947) technique whereby the two cultures to be crossed are washed, mixed and seeded onto unsupplemented minimal medium agar. Minimal medium plates dried at $37^{\circ}$ for $1 \mathrm{hr}$. were flooded with $2 \mathrm{ml}$. of the mixed bacterial suspension, thus distributing the bacteria evenly over the plates, and then dried while tilted at an angle from the horizontal. Controls to detect reverse mutation to prototrophy were carried out by seeding the separate mutants heavily on to minimal medium. The frequency of reverse mutation was always found to be negligible. Plates were then incubated for 2 or 3 days at $37^{\circ}$. The following crosses were attempted:
(1) $58-161^{\mathrm{R}} \times \mathrm{J} 4-5$.
(6) $58-161 \times \mathrm{J} \mathrm{4}-5^{\mathrm{R}}$.
(2) $58-161^{\mathrm{R}} \times \mathrm{J} \mathrm{5}-10$.
(7) $58-161 \times \mathrm{J} \mathrm{5}-10^{\mathrm{R}}$.
(3) $58-161^{\mathrm{R}} \times \mathrm{W} 677$.
(8) 58-161 $\times W 677$.
(4) $58-161^{\mathrm{R}} \times \mathrm{J} 4-5^{\mathrm{R}}$.
(9) J 4-5 $5^{\mathrm{R}} \times \mathrm{J} 5-10$.
(5) $58-161^{\mathrm{R}} \times \mathrm{J} 5-10^{\mathrm{R}}$.
(10) J 4-5 $\times$ J 5-10

Of these crossings only nos. (2), (3) and (8) yielded sufficiently large numbers of prototrophic colonies and experiments with the other crossings were abandoned.

In one series of experiments in which approximately $10^{9}$ cells of each of the two mutants were plated on minimal medium it was found that 58-161 $\times \mathrm{W} 677$ and $58-161^{\mathrm{R}} \times \mathrm{W} 677$ gave about 200 prototrophic colonies whilst $58-161^{\mathrm{R}} \times$ J 5-10 yielded 30 prototrophic colonies per plate. The control plates never gave more than four colonies (usually 0-2) with the same inoculum. The apparent infertility of the other crosses is probably to be explained by the recent work of Hayes (1953) in which he has shown that $K 12$ strains can exist in two mating types $\mathbf{F}+$ and $\mathbf{F}-$. It is probable that in many of the above crosses two $\mathbf{F}+$ types were used.

Colonies picked from the recombination plates were examined for valine sensitivity. When practicable, all the colonies on the plates were examined but where large numbers of colonies developed, all the colonies in sectors of the plates were examined. This examination was done by suspending the colony in sterile water and streaking a loopful of suspension up to a ditch 
containing $100 \mu \mathrm{g}$. DL-valine/ml. cut in a minimal medium plate. Striking differences were observed in the proportions of valine-resistant prototrophs derived from the various crossings.

The cross of 58-161 ${ }^{\mathrm{B}} \times \mathrm{J} \mathrm{5}-10$ showed a clear-cut segregation into completely resistant and completely sensitive colonies (Pl. 1, fig. 1). Of a total of 110 colonies tested, 64 were sensitive and 46 were fully resistant. These figures suggest that in the progeny of the cross there may be a slight preference in favour of valine-sensitive prototrophs. This may be due to factor linkage, as the same phenomenon has been encountered in the segregation of various factors in other crosses between $\mathrm{K} 12$ mutants (Lederberg, 1947).

A closer analysis of the location of the factor for valine resistance with respect to other factors on the bacterial chromosome was attempted. For these experiments the well-marked mutants 58-161 (B-, $\left.\mathbf{M}^{-}, \mathbf{T}^{+}, \mathrm{L}^{+}, \mathrm{B}_{\mathbf{1}}{ }^{+}\right)$and W $677\left(\mathbf{B}^{+}, \mathbf{M}^{+}, \mathbf{T}^{-}, \mathbf{L}^{-}, \mathbf{B}_{\mathbf{1}}^{-}\right)$were used. The symbols $\mathbf{B}^{-}, \mathbf{M}^{-}$, etc., indicate requirement for biotin, methionine, etc., whereas $\mathrm{B}^{+}, \mathrm{M}^{+}$, etc., indicate that the organism is independent of these factors.

The W677 mutant cannot be grown in the absence of leucine from the medium. As leucine neutralizes the inhibitory effect of valine (Rowley, 1953) the question arises whether the valine resistance in $\mathrm{W} 677$ lies solely in the presence of leucine in its medium, in other words that valine resistance in W 677 is merely phenotypical. The alternative is that the resistance to valine of W677 has an endogenous basis, i.e. it is genotypical and can then be compared with induced valine-resistant strains such as the $58-161^{\mathbf{R}}$ strain. A definite answer to this question can only be given by a crossing experiment. Should W677 prove to be genotypically sensitive, then on crossing with the valine-sensitive 58-161 it would behave as if it were a cross of the type $\mathrm{Val}^{\mathrm{s}} \times \mathrm{Val}^{\mathrm{s}}$ and all the progeny would inevitably be valine sensitive. If, however, valine resistance of $W 677$ were genotypical, then a crossing with the sensitive 58-161 would be of the type $\mathrm{Val}^{\mathrm{B}} \times \mathrm{Val}^{\mathbb{R}}$ and consequently a mixture of sensitive and resistant progeny would be expected. The experimental crossing yielded colonies (191) all of which were sensitive to valine (Pl. 1, fig. 2). This is consistent with $\mathrm{W} 677$ being genotypically sensitive to valine. From this conclusion it was to be expected that the cross of W677 $\times$ $58-161^{B}$ would yield a mixture of sensitive and resistant colonies as was the case with J5-10 $\times 58-161^{\mathrm{R}}$. However, the progeny from crossing W677 $\times$ 58-161 ${ }^{\mathrm{R}}$ comprised 218 colonies all of which were resistant to $100 \mu \mathrm{g}$. valine/ml. (Pl. 1, fig. 3).

The problem arises as to how we can reconcile the results of crossing $58-161^{\mathrm{R}} \times \mathrm{J} 5-10$ with those from crossing $58-161^{\mathrm{R}} \times \mathrm{W} 677$. The most likely explanation would seem to be that there is a strong linkage of valine resistance to one or more of the factors responsible for prototrophy. In the cross W677 $\times 58-161^{\mathrm{R}}$ the factors implicated are $\left(\mathrm{B}^{+}, \mathrm{M}^{+}, \mathrm{T}^{+}, \mathrm{L}^{+}, \mathrm{B}_{1}{ }^{+}\right)$but only the latter three need be considered since $\mathrm{B}^{+} . \mathrm{M}^{+}$play a role in the cross $\mathrm{J}$ 5-10 $\times$ 58- $161^{\mathrm{B}}$ where no linkage between valine resistance and factors for prototrophy $\left(\mathbf{P}^{+}, \mathbf{H}^{+}, \mathbf{B}^{+}, \mathbf{M}^{+}\right)$were found. It has been shown that the factor for thiamine independence, $\mathrm{B}_{1}{ }^{+}$, and the two factors for threonine and leucine 
independence, $\mathrm{T}^{+}, \mathrm{L}^{+}$, are located on the chromosome in distal positions (Lederberg, 1947; Cavalli, 1952). It seems likely therefore that the locus for valine resistance is situated either near to that for thiamine independence or in the vicinity of the threonine and leucine loci.

To decide between these alternatives $\mathrm{W} 677 \times 58-161^{\mathrm{R}}$ were crossed on minimal medium supplemented with $20 \mu \mathrm{g}$. thiamine/ml.; thiamine is not antagonistic to valine inhibition. Crossing on this medium does not select for thiamine independence $\left(\mathbf{B}_{1}{ }^{+}\right)$, and therefore $\mathbf{B}_{1}-$ recombinants can also develop. Considering the exceptionally high degree of linkage to be accounted for, in the hypothetical case of linkage of $\mathrm{Val}^{\mathrm{R}}$ to $\mathrm{B}_{1}^{+}$, or the equivalent of $\mathrm{Val}^{\mathrm{s}}$ to $B_{1}{ }^{-}$, we expect all, or at least nearly all, $B_{1}-$ recombinants to be sensitive to valine. Since we expect that among the $B_{1}{ }^{+}$and $B_{1}-$ recombinants the $B_{1}{ }^{-}$ class will prevail (Lederberg, 1947), linkage of $\mathrm{Val}^{\mathrm{s}}$ to $\mathrm{B}_{\mathbf{1}}-$ would be apparent if the majority of colonies developing on thiamine supplemented plates were sensitive. If this should not be found, the alternative of linkage of $\mathrm{Val}^{\mathbb{R}}$ to $\mathrm{T}^{+}$ and $\mathrm{L}^{+}$would hold true by elimination.

In the experiment colonies were picked and assayed for valine resistance (ditch plate technique) and thiamine requirement (presence or absence of growth on minimal medium). From a total of 62 colonies, 57 were thiamine dependent (as anticipated), yet not one valine-sensitive colony was found. This eliminates the possibility of linkage between $\mathrm{Val}^{\mathrm{B}}$ and $\mathrm{B}_{\mathbf{1}}^{-}$, or $\mathrm{Val}^{\mathrm{R}}$ and $\mathrm{B}_{1}^{+}$, and leaves us with the alternative conclusion that $\mathrm{Val}^{\mathrm{R}}$ must be linked with the $\mathrm{T}^{+}$or $\mathrm{L}^{+}$factors.

Finally, to decide whether $\mathrm{Val}^{\mathrm{R}}$ is linked with the $\mathrm{T}$ or the $\mathrm{L}$ factors $58-161^{\mathrm{R}} \times \mathrm{W} 677$ were seeded onto plates supplemented with threonine. Out of a total of 147 recombinant colonies (all threonine independent) only 7 , or $5 \%$, were of normal sensitivity to valine. The very high yield $(95 \%)$ of $\mathrm{Val}^{\mathrm{R}}$ colonies in this experiment suggests that the factor for valine resistance is situated in the close proximity of the $L$ locus. A more definite conclusion as to the exact relation of $\mathrm{Val}^{\mathrm{R}}$ with respect to $\mathrm{L}^{+}$or $\mathrm{T}^{+}$cannot be given, since the position of $\mathbf{T}^{+}$relative to $\mathbf{L}^{+}$is still undetermined (Lederberg, Lederberg, Zinder \& Lively, 1951).

\section{DISCUSSION}

The development of resistance to valine in the K12 strain of Bact. coli may be unique in that it appears to occur by one step only. So far as we are aware this obligatory one-step development of resistance has only been described previously in the case of Mycobacterium tuberculosis and isonicotinic acid hydrazide (Middlebrook, 1952). In that instance, however, only a 15-fold range of concentration was examined, compared with a 1000-fold range in the present work. The crossing experiments fully confirm this one-step development of resistance since a clear-cut segregation of the progeny into fully resistant and fully sensitive strains was found.

Resistance to valine was found to be permanent, in common with resistance to some antibiotics, e.g. streptomycin. Attempts were made to isolate valinedependent strains by similar techniques to those used by Miller \& Bohnhoff 
(1947) in isolating streptomycin-dependent variants of meningococci. Minimal medium plates containing $1000 \mu \mathrm{g}$. DL-valine/ml. were seeded with $\mathrm{K} 12$ and incubated for several days. Each day the newly developed colonies were examined for valine dependence by streaking on minimal medium ditch plates with a solution containing $100 \mu \mathrm{g}$. DL-valine $/ \mathrm{ml}$. in the ditch. Occasional valine-dependent strains were met but they were very unstable, quickly reverting to normal valine resistance. These dependent strains could in no way be compared with the stable amino-acid dependent mutants of $\mathrm{K} 12$ which have been isolated by other well-known methods (Lederberg, 1947).

In the recombination data summarized in Table 3, Exps. 2 and 3 yield conflicting results. From Exp. 2 we deduce that W677 is genotypically sensitive and from Exp. 3 we may draw exactly the opposite conclusion. One of these crosses must be complicated by a very strong linkage to factors for prototrophy. It seems quite possible that either $\mathrm{Val}^{\mathrm{s}}$ or $\mathrm{Val}^{\mathrm{B}}$ might be linked to $\mathrm{L}^{+} \mathrm{T}^{+}$or $\mathrm{B}_{1}{ }^{+}$. However, since all the other $\mathrm{K} 12$ mutants above are valine sensitive, it seems likely that W677 is genotypically sensitive also. Furthermore experiment 5 , in which 7 sensitive recombinant colonies developed, proves that $\mathrm{W} 677$ must be $\mathrm{Val}^{\mathrm{s}}$, otherwise the progeny of its cross with $58-161^{R}$ would always be $\mathrm{Val}^{\mathrm{R}}$.

\section{Table 3. Summary of recombination data}

\begin{tabular}{|c|c|c|c|c|}
\hline \multirow{2}{*}{$\begin{array}{c}\text { Exp. } \\
\text { no. }\end{array}$} & \multirow[b]{2}{*}{ Cross } & \multirow[b]{2}{*}{ Supplements } & \multicolumn{2}{|c|}{ Colonies developing } \\
\hline & & & $\mathrm{Val}^{\mathrm{R}}$ & $\mathrm{Val}^{\mathrm{B}}$ \\
\hline $\mathbf{1}$ & $58-161^{\mathrm{R}} \times \mathrm{J} 5-10$ & None & 46 & 64 \\
\hline 2 & $58-161 \times W 677$ & None & $\mathbf{0}$ & 191 \\
\hline $\mathbf{3}$ & $58-161^{\mathrm{B}} \times \mathrm{W} 677$ & None & 218 & o \\
\hline 4 & $58-161^{\mathrm{R}} \times \mathrm{W} 677$ & $\mathbf{B}_{1}$ & 62 & $\mathbf{0}$ \\
\hline 5 & $58-161^{\mathrm{R}} \times \mathrm{W} 677$ & $\mathbf{T}$ & 140 & 7 \\
\hline
\end{tabular}

Control plates seeded with equivalent concentrations of each parent alone never showed more than four colonies.

A new approach to linkage data in $\mathrm{K} 12$ is necessary as a result of the recent work of Hayes (1953), and of Cavalli, Lederberg \& Lederberg (1953). These authors have shown quite clearly the occurrence of two mating types designated $\mathbf{F}+$ and $\mathbf{F}-$; crosses of $\mathbf{F}-\times \mathbf{F}-$ are sterile and maximum fertility is shown by $\mathrm{F}+\times \mathrm{F}-$ crosses. In the opinion of Hayes, the $\mathrm{F}-$ parent plays a more passive acceptor role, and in order to form a prototrophic recombinant from auxotrophic $\mathbf{F}+$ and $F$ - strains, the donor $F+$ strain must transfer the prototrophic loci which the $\mathbf{F}$ - form lacks. It is apparent, however, that only a part of the $\mathbf{F}+$ chromosome is transferred to the $\mathbf{F}-$ cell. Exactly what this part is depends of course on the conditions of selection used in any experiment. Thus in a cross such as we have used, between $58-161 / F+$ and $W 677 / F-$, seeded on to minimal medium, there is selection for the $\mathbf{T L}+$ part of the $\mathbf{F}+$ chromosome and also for the $\mathbf{B}_{1}+$ part. Any unselected markers in these portions of the $\mathbf{F}+$ chromosome will tend to be carried over simultaneously. The degree to which they are carried over will depend on their proximity to the selected markers. 
On the basis of these new concepts the data above can be re-interpreted as follows. Exps. 2 and 3 of Table 3, in both of which there is selection for TL + and $\mathrm{B}_{1}+$, show that $\mathrm{Val}^{\mathrm{s}}$ and $\mathrm{Val}^{\mathrm{R}}$ are associated either with the TL region or with the $B_{1}$ region. Exp. 4, however, eliminates selection for $B_{1}+$, nevertheless all the recombinants have the same $\mathrm{Val}^{\mathrm{R}}$ as the $\mathrm{F}+$ parent, showing that the factor controlling valine resistance is located in the TL region and presumably very close to the TL loci. Exp. 5 confirms this and since there is some separation of the $\mathrm{Val}^{\mathbb{R}}$ marker from the TL markers, one must conclude that $\mathrm{Val}^{\mathrm{R}}$ is very close to, but certainly not identical with, the TL loci. The results from Exp. 1 are very probably due to an $\mathbf{F}+\times \mathbf{F}+$ cross. This has been shown by Hayes to behave qualitatively as an $\mathrm{F}+\times \mathrm{F}$ - cross mixed with the same cross of reversed F polarity. Thus Exp. 1 would be expected to yield a mixture of progeny from the two crosses below :

(a) $\mathrm{Val}^{\mathrm{R}} \cdot \mathbf{M}-/ \mathbf{F}+\times \mathrm{Val}^{\mathrm{s}} \cdot \mathbf{P}-\mathbf{H}-/ \mathbf{F}-$ (selection for $\mathbf{P}+\mathbf{H}+$ ),

(b) $\mathrm{Val}^{\mathrm{R}} \cdot \mathbf{M}-/ \mathbf{F}-\times \mathrm{Val}^{\mathrm{s}} . \mathbf{P}-\mathbf{H}-/ \mathbf{F}+$ (selection for $\mathbf{M}+$ ).

Since neither of these crosses involves transfer of the TL region there will be no transfer of the associated Val factor and the prototrophs will have the same valine sensitivity as the $\mathrm{F}$ - parent. The result will be a mixture of valine-sensitive and valine-resistant prototrophs in the ratio of the efficiency of the two recombining systems.

The conclusions, as to the position of $\mathrm{Val}^{\mathrm{R}}$ in the TL region, remain valid. The reasoning, by which this conclusion was reached earlier in the discussion, must now be considered as invalid and is only included in order to demonstrate, as Hayes has already done, the difficulties in postulating linkages without carefully considering the $\mathbf{F}+$ polarity of the cross. The crossing experiments show that valine resistance is controlled by one gene which is closely linked with the gene for leucine synthesis.

It is tempting to speculate that the highly specific reversal of valine inhibition of $\mathrm{K} 12$ by leucine may be a direct result of the close proximity of these two governing genes.

We are grateful to Sir Alexander Fleming for his continued encouragement and to Professor R. Cruickshank for helpful criticism of this paper. The mutants W677 and 58-161 were kindly supplied by Dr Forrest Fulton of the London School of Hygiene and Tropical Medicine, and we are indebted to Dr B. D. Davis of the U.S. Public Health Service, Tuberculosis Research Laboratory, New York for the other mutants. Finally, we wish to thank Dr W. Hayes of the Postgraduate Medical School, London, for his illuminating discussions on these problems. One author (A. M.) began this study during the tenure of a W.H.O. Followship at the WrightFleming Institute.

\section{REFERENCES}

Bryson, V. \& Szybalski, W. (1952). Microbial selection. Science, 116, 45.

Cavalli, L. L. (1952). Genetic analysis of drug-resistance. Bull. World Hlth Org. $6,185$.

Cavali, L. L., Lederberg, J. \& Lederberg, E. M. (1953). An infective factor controlling sex compatibility in Bacterium coli. J. gen. Microbiol. 8, 89.

Davis, B. D. \& Mingroli, E. S. (1950). Mutants of Escherichia coli requiring methionine or vitamin B12. J. Bact. 60, 17. 
Journal of General Microbiology, Vol. 9, No. 2
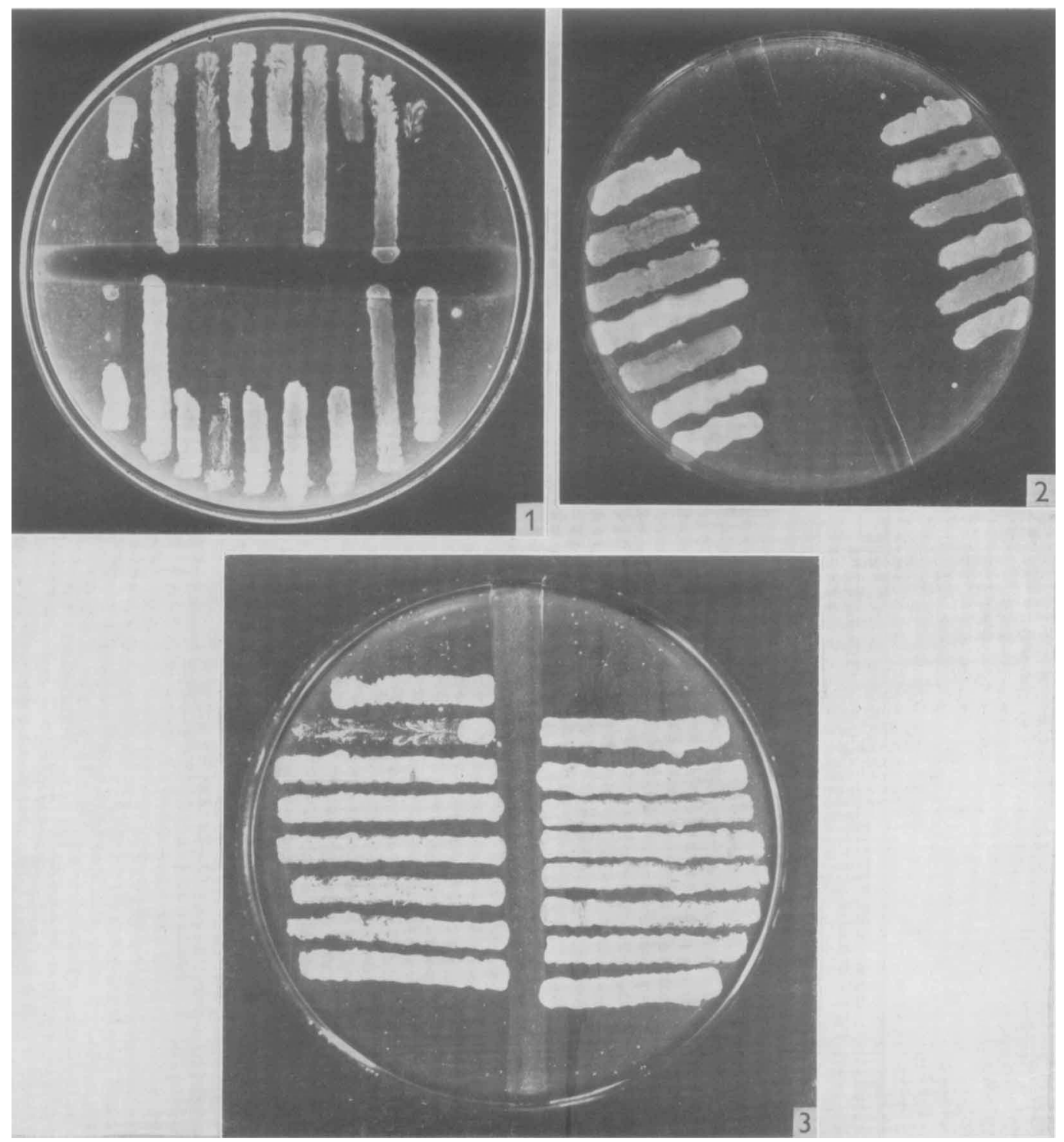

A. Manten \& D. Rowley-Valine inhibition in Bact. coli. Plate 1 
HaYes, W. (1953). Observations on a transmissible agent determining sexual differentiation in Bacterium coli. J. gen. Microbiol. 8, 72.

Hsie, J. Y. \& Bryson, V. (1950). Genetic studies in the development of resistance to neomycin and dihydrostreptomycin in Mycobacterium ranae. Amer. Rev: Tuberc. $62,286$.

LEDERBERg, J. (1947). Gene recombination and linked segregations in Escherichia coli. Genetics, 32, 505.

Lederberg, J., Lederberg, E. M., Zinder, N. D. \& Lively, E. R. (1951). Recombination analysis of bacterial heredity. Cold Spr. Harb. Sym. quant. Biol. $16,413$.

Lederberg, J. \& TAtum, E. L. (1946). Gene recombinations in Escherichia coli. Nature, Lond. 158, 558.

Middlebrook, G. (1952). Sterilization of tubercle bacilli by isonicotinic acid hydrazide and the incidence of variants resistant to the drug in vitro. Amer. Rev. Tuberc. 65, 765 .

Mruler, C. P. \& Bohnhoff, M. (1947). Two streptomycin resistant variants of meningococcus. J. Bact. 54, 467.

Rowlex, D. (1953). Inhibition of Escherichia coli strains by amino acids. Nature, Lond. 171, 80.

Tatum, E. L. (1949). Amino-acid metabolism in mutant strains of microorganisms. Fed. Proc. 8, 511.

Tatum, E. L. \& Lederberg, J. (1947). Gene recombination in the bacterium Escherichia coli. J. Bact. 53, 673.

\section{EXPLANATION OF PLATE}

Fig. 1. Prototrophic colonies from the cross 58-161 ${ }^{\mathrm{R}} \times \mathrm{J} 5-10$ tested on minimal medium ditch plates. $100 \mu \mathrm{g}$. DL-valine $/ \mathrm{ml}$. in the ditch.

Fig. 2. Result of the cross 58-161 $\times$ W677. Note all recombinants sensitive to $100 \mu \mathrm{g}$. DL-valine $/ \mathrm{ml}$.

Fig. 8. Result of the cross $58-161^{\mathrm{R}} \times \mathrm{W} 67 \%$. Note all recombinants resistant to $100 \mu \mathrm{g}$. DL-valine/ml.

(Received 11 March 1953) 